\title{
Microstructure and Electrical Conductivity of Yttria Stabilized Zirconia (8Y-CSZ) Containing Small NiO Addition
}

\author{
Bulent Aktas ${ }^{1}$ and Cemal Carboga ${ }^{2}$ \\ 1. Harran University, Engineering Faculty, Mechanical Engineering, Sanliurfa, Turkey \\ 2. Nevsehir University, Engineering Faculty, Materials Science Engineering, Nevsehir, Turkey
}

Received: March 12, 2013 / Accepted: April 16, 2013 / Published: November 25, 2013.

\begin{abstract}
In this study, the effect of addition in small contents of $\mathrm{NiO}$ on microstructure and electrical conductivity properties of $8 \mathrm{~mol} \%$ yittria stabilized cubic zirconia (8Y-CSZ) were investigated. Specimens were produced by colloidal processing from $1 \mathrm{wt} \%$ $\mathrm{NiO}$ and $99 \mathrm{wt} \% 8 \mathrm{Y}-\mathrm{CSZ}$ powders. Specimens were pressurelless sintered at $1,400{ }^{\circ} \mathrm{C}$ for $10 \mathrm{~h}$. Scanning Electron Microscope (SEM) and EDS analysis results showed that an amount of $1 \mathrm{wt} \% \mathrm{NiO}$ dissolved in the $8 \mathrm{Y}-\mathrm{CSZ}$ and insoluble NiO in the $8 \mathrm{Y}-\mathrm{CSZ}$ precipitated at the grain boundaries. Electrical conductivities of undoped and $1 \mathrm{wt} \% \mathrm{NiO}$ doped $8 \mathrm{Y}$-CSZ specimens were measured using a frequency response analyzer (impedance spectroscopy) in the frequency range of $100 \mathrm{mHz}-13 \mathrm{MHz}$ and at $300-800{ }^{\circ} \mathrm{C}$. Electrical conductivity results showed that grain interior, grain boundary and total conductivity of $8 \mathrm{Y}-\mathrm{CSZ}$ increased with $1 \mathrm{wt} \%$ $\mathrm{NiO}$ addition. The reason for increase of electrical conductivity in NiO doped 8Y-CSZ, due to create oxygen vacancies in the crystal lattice of dissolved $\mathrm{NiO}$ in $8 \mathrm{Y}-\mathrm{CSZ}$ and the ion transfer of the oxygen vacancies at high temperatures.
\end{abstract}

Key words: Cubic zirconia (8Y-CSZ), NiO, electrical conductivity, impedance spectroscopy.

\section{Introduction}

Solid oxide fuel cell (SOFC) is a device, which is produced the electricity with the aid of an electrolyte having ionic conductivity electro-chemically and combination with a gaseous fuel, and oxidizing gas. Solid Oxide Fuel Cells operating between 700 and $1,000{ }^{\circ} \mathrm{C}$ generate the electricity between $1 \mathrm{~kW}$ and 10 MW at $65 \%$ efficiency [1]. The ions in a SOFC are transmitted from a porous electrode (cathode) to an electrolyte and from inside an electrolyte to a porous fuel electrode (anode). Oxygen ions in the SOFC react with the fuel $\left(\mathrm{H}_{2}\right.$, natural gas, methane, etc.) and release electrons to external circuit to generate electricity. Thus, it occurs $1 \mathrm{~V}$ potential between anode and cathode. Yttria-stabilized cubic zirconia

Corresponding author: Bulent Aktas, Ph.D., asistant professor, research fields: powder metallurgy, sintering, mechanical and electrical properties of zirconia ceramics. E-mail: baktas@harran.edu.tr.
(8Y-CSZ) is generally used as an electrolyte material that is perfectly conducted oxygen ions from cathode to anode at high temperatures. $\mathrm{NiO} / \mathrm{Y}_{2} \mathrm{O}_{3}-\mathrm{ZrO}_{2}$ $(\mathrm{Ni} / \mathrm{YSZ})$ cermet is used as an anode material. Lanthanum Manganate $\left(\mathrm{LaMnO}_{3}\right)$ peroxide having electronic and ionic conductivity is used as a cathode material [2-4].

Pure zirconia has three different polymorphic transformations such as monoclinic, tetragonal and cubic. These phases can be obtained as depending on temperature and composition at equilibrium conditions. $\mathrm{ZrO}_{2}$ has a monoclinic crystalline range from room temperature to $1,170{ }^{\circ} \mathrm{C}$. Monoclinic $\mathrm{ZrO}_{2}$ transforms into tetragonal crystalline at $1,170{ }^{\circ} \mathrm{C}$ with a 5\% volume reduction, and tetragonal crystalline transforms into cubic crystalline at $2,370{ }^{\circ} \mathrm{C}$. Cubic crystalline is stable up to $2,680{ }^{\circ} \mathrm{C}$ which is the melting temperature of zirconia. It must form a solid 
solution with metal oxides such as $\mathrm{MgO}, \mathrm{CaO}, \mathrm{CeO}_{2}$ and $\mathrm{Y}_{2} \mathrm{O}_{3}$ in order to make the stable of cubic zirconia at room temperatures [5-7].

It has several advantages for mixed conductive composites in the selection of $\mathrm{NiO}$ as an electronic component. $\mathrm{NiO}$ is stable at a wide temperature range and partial oxygen pressures [8]. $\mathrm{NiO}$ is also known as excellent a catalyst for the activation of oxygen [9]. In addition to conductivity of $\mathrm{NiO} ; \mathrm{NiO}$ is easily compatibles with additives as Lithium when it is needed. Therefore, when the optimum composition of $\mathrm{NiO}$ in the $8 \mathrm{Y}-\mathrm{CSZ}$ was determined, $8 \mathrm{Y}-\mathrm{CSZ} / \mathrm{NiO}$ composites may be promising as cathode material [10].

In this study, the effect of addition in a small amount of $\mathrm{NiO}$ on microstructure and electrical conductivity properties of the $8 \mathrm{Y}$-CSZ using as SOFC were investigated.

\section{Experimental Materials and Procedure}

In this study, $8 \mathrm{~mol} \%$ yttria stabilized cubic zirconia (8Y-CSZ) (Tosoh, Japan) powders and NiO powders (MTI Industrial Co. USA) up to $1 \mathrm{wt} \%$ were used as matrix material and additives, respectively. The average grain sizes were $0.3 \mu \mathrm{m}$ for $8 \mathrm{Y}-\mathrm{CSZ}$ and 0.3 $\mu \mathrm{m}$ for NiO. The chemical compositions of the powders used in the experiments are presented in Table 1.

The specimens for the microstructural and electrical conductivity investigations were produced by means of colloidal processing. The doping process was carried out in a plastic container by mechanical mixing of $\mathrm{NiO}$ up to $1 \mathrm{wt} \%$ and $8 \mathrm{Y}-\mathrm{CSZ}$ powders with zirconia balls and ethanol. The mechanical mixing was done in a "speks" type mixer at $200 \mathrm{rpm}$ for $12 \mathrm{~h}$. The prepared slurries were left to dry for 24 $\mathrm{h}$ by leaving the lid open. After the drying process, the agglomerated powders with medium hardness were ball milled for $10 \mathrm{~min}$ to obtain a good dispersion and to break up the agglomerates. The powders obtained were sieved through a $60 \mu \mathrm{m}$ sift and pressed under $200 \mathrm{MPa}$ of pressure in a single axis die with a radius of $10 \mathrm{~mm}$ and a height of $4 \mathrm{~mm}$. The inner surface of the steel die was cleaned after each dry pressing process, and stearic acid was applied to the side walls of the die.

Sintering was carried out in a box type furnace under normal atmospheric conditions. The pressed pellets were sintered at $1,400{ }^{\circ} \mathrm{C}$ for $10 \mathrm{~h}$ at heating and cooling rates of $5{ }^{\circ} \mathrm{C} / \mathrm{min}$. The surfaces of the specimens were ground and polished using normal metallographic methods after the sintering process, and the specimens were thermally etched by keeping them in a furnace at $50{ }^{\circ} \mathrm{C}$ below the sintering temperature for $1 \mathrm{~h}$. Microstructural investigation of the sintered specimens was performed using a scanning electron microscope (SEM Jeol Lv 6060). Grain sizes were measured using the mean linear intercept method.

The electrical conductivity measurements were carried out with pellet specimens with a $10 \mathrm{~mm}$ diameter and about $3 \mathrm{~mm}$ thickness. The two surfaces of each sintered pellet were slightly polished with abrasive paper, and platinum paste was applied to both sides of the specimens. The specimens were then dried in an oven at $100{ }^{\circ} \mathrm{C}$ to eliminate the solvent and annealed at $800{ }^{\circ} \mathrm{C}$ for $30 \mathrm{~min}$ to avoid an excessive shrinkage of the platinum electrodes. The temperature dependence of electrical conductivity was measured using a frequency response analyzer (Solartron Model 1260 ) in the frequency range of $100 \mathrm{mHz}-13 \mathrm{MHz}$. Measurements were made in the air and in the temperature range of $300-800^{\circ} \mathrm{C}$ at an interval of

Table 1 The chemical composition of powders used in the experimental works.

\begin{tabular}{lllllllllll}
\hline \multirow{2}{*}{ Powders } & \multicolumn{10}{c}{ wt\% } \\
\cline { 2 - 11 } & $\mathrm{ZrO}_{2}$ & $\mathrm{Y}_{2} \mathrm{O}_{3}$ & $\mathrm{MgO}$ & $\mathrm{NiO}$ & $\mathrm{TiO}_{2}$ & $\mathrm{FeO}_{2}$ & $\mathrm{Na}_{2} \mathrm{O}_{3}$ & $\mathrm{CaO}$ & $\mathrm{Al}_{2} \mathrm{O}_{3}$ & $\mathrm{SiO}_{2}$ \\
\hline $8 \mathrm{Y}-\mathrm{CSZ}$ & 85.9 & 13.6 & - & - & 0.1 & 0.003 & 0.01 & 0.02 & 0.25 & 0.1 \\
$\mathrm{NiO}$ & - & - & $<0.01$ & 99.8 & - & $<0.012$ & $<0.01$ & $<0.01$ & - & - \\
\hline
\end{tabular}


$100{ }^{\circ} \mathrm{C}$. The Ac impedance diagrams were analyzed using Zview software.

\section{Results and Discussion}

The microstructures of the undoped and $1 \mathrm{wt} \% \mathrm{NiO}$ doped $8 \mathrm{Y}$-CSZ specimens sintered at $1,400{ }^{\circ} \mathrm{C}$ for $10 \mathrm{~h}$ are presented in Fig. 1. The microstructure of the undoped 8Y-CSZ showed that it was composed of coarse-grained and coaxial polygonal grains (Fig. 1a) and the microstructure of $1 \mathrm{wt} \% \mathrm{NiO}$ doped $8 \mathrm{Y}-\mathrm{CSZ}$ specimen formed a smaller and more fine-grained structure (Fig. 1b). Due to the fact that $1 \mathrm{wt} \% \mathrm{NiO}$ doped $8 \mathrm{Y}-\mathrm{CSZ}$ specimen has a lower grain boundary diffusion, it slowed down the movement of grain boundaries and occurred the less grain growth in the $1 \mathrm{wt} \% \mathrm{NiO}$ doped $8 \mathrm{Y}-\mathrm{CSZ}$. The main differences in microstructure of the sintered specimens are change in the grain size and amount of porosity. Batista et al. reported that the addition of small amount of $\mathrm{NiO}$ into $8 \mathrm{Y}-\mathrm{CSZ}$ slightly slowed down the grain growth and increased densification of $8 \mathrm{Y}-\mathrm{CSZ}$ [11].

The changes in the grain size of the undoped and 1 $\mathrm{wt} \% \mathrm{NiO}$ doped $8 \mathrm{Y}-\mathrm{CSZ}$ specimens are presented in Fig. 2. The addition of $1 \mathrm{wt} \% \mathrm{NiO}$ brought about a slight decrease in the grain size of $8 \mathrm{Y}$-CSZ. The grain sizes of undoped and $1 \mathrm{wt} \% \mathrm{NiO}$ doped $8 \mathrm{Y}-\mathrm{CSZ}$ specimens were calculated as 4.15 and $3.61 \mu \mathrm{m}$, respectively. Due to precipitation in low amount of
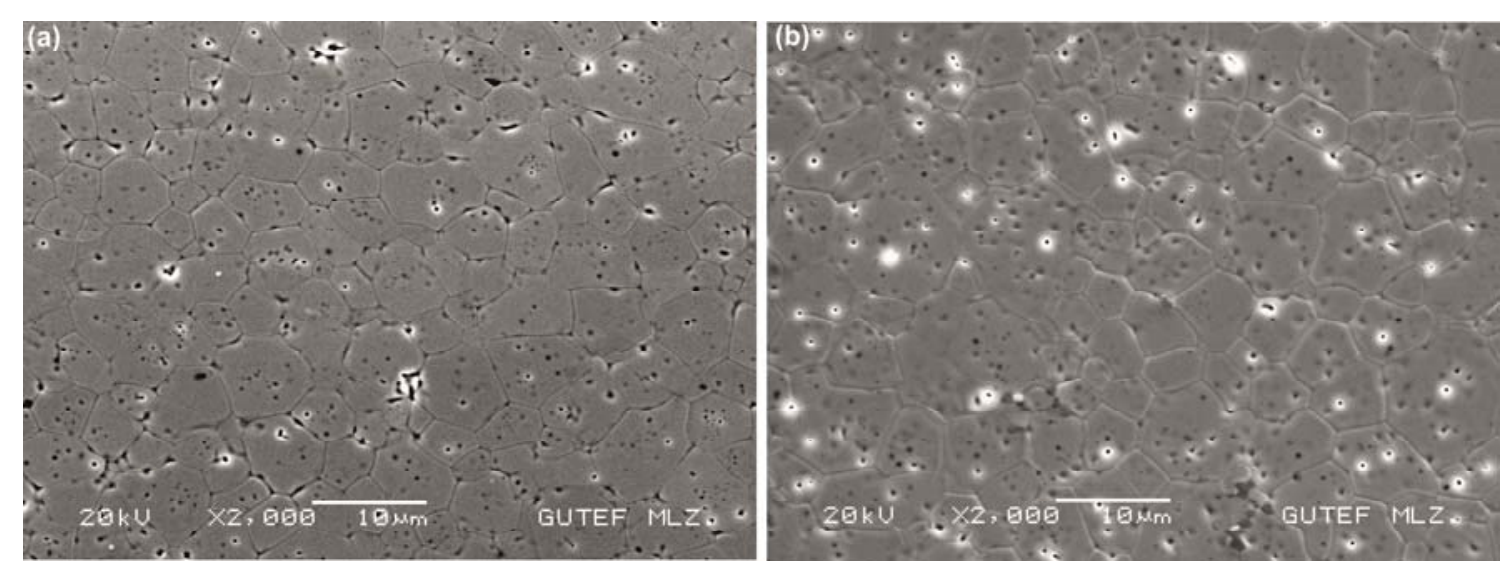

Fig. 1 The microstructures of the undoped and $1 \mathrm{wt} \% \mathrm{NiO}$ doped $8 \mathrm{Y}$-CSZ specimens sintered at $1,400{ }^{\circ} \mathrm{C}$ for $10 \mathrm{~h}$. (a) Undoped 8Y-CSZ and (b)1 wt\% NiO doped 8Y-CSZ.
$\mathrm{Y}_{2} \mathrm{O}_{3}$ at the grain boundaries of $8 \mathrm{Y}-\mathrm{CSZ}$ and high-energy at grain boundaries, the grain size of the undoped $8 \mathrm{Y}-\mathrm{CSZ}$ is larger than $\mathrm{NiO}$ doped $8 \mathrm{Y}-\mathrm{CSZ}$ [12].

$\mathrm{NiO}$, which precipitated at the grain boundaries of 8Y-CSZ restricted the movement of grain boundaries with solid solution drag mechanism. The necessary condition for solid solution drag is precipitation at the grain boundaries of one of the components of solid solution.

EDS analysis results of $1 \mathrm{wt} \% \mathrm{NiO}$ doped $8 \mathrm{Y}-\mathrm{CSZ}$ sintered at $1,400{ }^{\circ} \mathrm{C}$ for $10 \mathrm{~h}$ are presented in Fig. 3. $1 \mathrm{wt} \% \mathrm{NiO}$ completely didn't dissolve in the 8Y-CSZ. EDS results showed that $\mathrm{NiO}$ insoluble in the $8 \mathrm{Y}-\mathrm{CSZ}$ segregated at the grain boundaries.

The measurement of electrical conductivity is one of the important requirements for an electrolyte in Solid Oxide Fuel Cells. As reported earlier, generally, the Ac impedance of an ionic conductor contains contributions from grain, the grain boundary and electrode-electrolyte interface at high, intermediate and low frequencies, respectively, which can be reflected in a complex plane by three successive arcs $[13,14]$. A schematic plot of the complex impedance for zirconia and its equivalent electrical circuit was originally proposed by Bauerle [15]. The Ac impedance spectroscopies of $1 \mathrm{wt} \% \mathrm{NiO}$ doped $8 \mathrm{Y}-\mathrm{CSZ}$ specimen at different temperatures are shown in Fig. 4. 


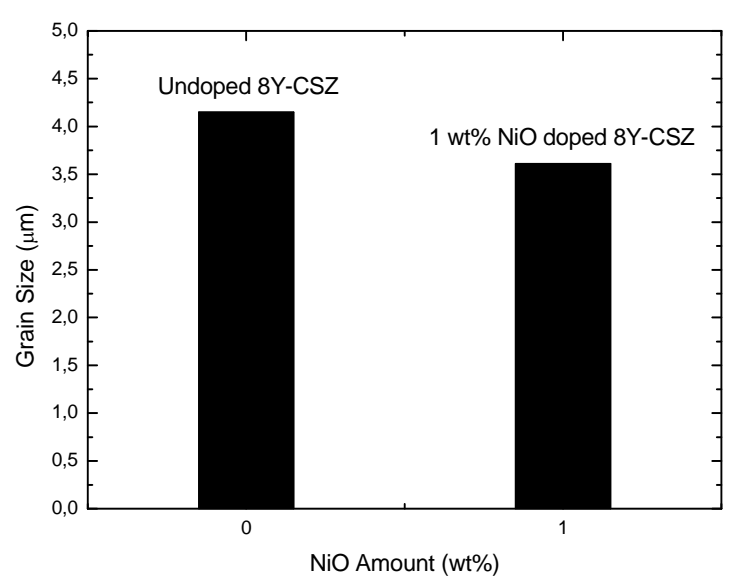

Fig. 2 The average grain sizes of the undoped and $1 \mathrm{wt} \%$ NiO doped 8Y-CSZ specimens.

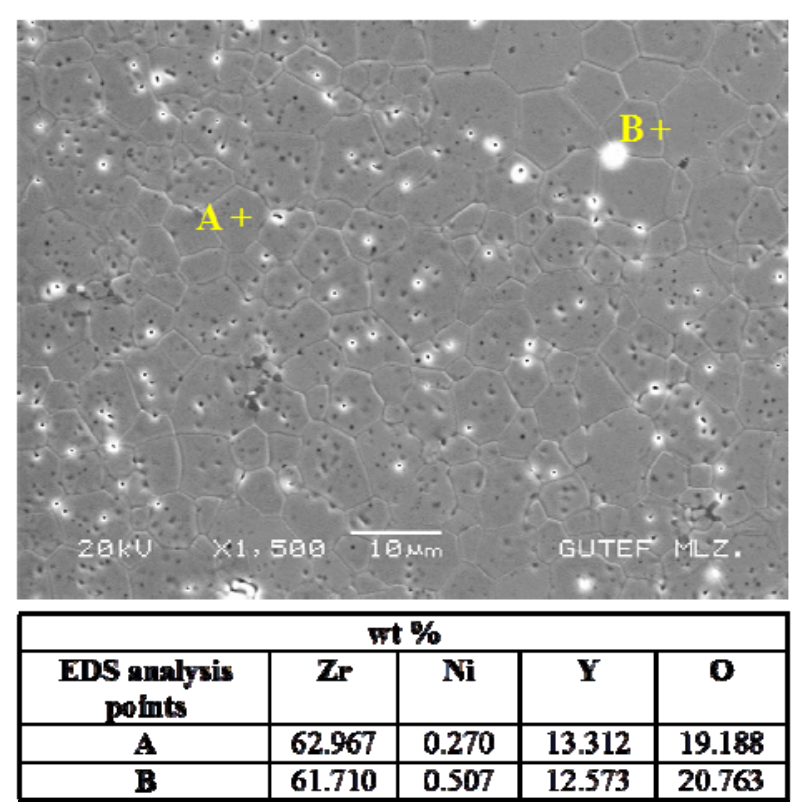

Fig. 3 EDS results of $1 \mathrm{wt} \% \mathrm{NiO}$ doped $8 \mathrm{Y}-\mathrm{CSZ}$ specimen sintered at $1,400{ }^{\circ} \mathrm{C}$ for $10 \mathrm{~h}$.

When ac empedance curves of the $1 \mathrm{wt} \% \mathrm{NiO}$ doped 8Y-CSZ specimen examined in Fig. 4, grain interior resistance $\left(\mathrm{R}_{\mathrm{gi}}\right)$ is lower than grain boundary resistance $\left(\mathrm{R}_{\mathrm{gb}}\right)$. It was obtained three semicircles at 300,400 and $500{ }^{\circ} \mathrm{C}$ in the $1 \mathrm{wt} \% \mathrm{NiO}$ doped $8 \mathrm{Y}-\mathrm{CSZ}$ (Figs. 4a-4c). But it wasn't obtained three semicircles at temperatures above $500{ }^{\circ} \mathrm{C}$ (Figs. $4 \mathrm{~d}-4 \mathrm{f}$ ) and, it was seen that the electrical circuit model changed as depending on each temperature.

The grain interior $\left(\sigma_{\mathrm{gi}}\right)$ and grain boundary conductivity $\left(\sigma_{\mathrm{gb}}\right)$ were calculated using the following Eq. (1):

$$
\begin{gathered}
\sigma_{g i}=\frac{1}{R_{g i}} \cdot \frac{L}{A} \\
\sigma_{g b}=\frac{1}{R_{g b}} \cdot \frac{L}{A}
\end{gathered}
$$

where, $R_{g i}$ is the grain interior resistance, $R_{g b}$ is the grain boundary resistance, and $L$ and $A$ are the thickness of the specimen and cross-sectional area of the specimen, respectively.

The effect of $\mathrm{NiO}$ content on the grain interior, the grain boundary and total conductivity of $8 \mathrm{Y}-\mathrm{CSZ}$ at $400{ }^{\circ} \mathrm{C}$ was presented in Fig. 5. The electrical conductivity results showed that the addition in a small amount of $\mathrm{NiO}$ into $8 \mathrm{Y}-\mathrm{CSZ}$ brought about an increase in the grain interior, grain boundary and total conductivities. $\mathrm{NiO}$, which dissolved in the $8 \mathrm{Y}-\mathrm{CSZ}$ crystal structure and precipitated at the grain boundaries, disrupted charge neutrality of crystalline of the $8 \mathrm{Y}-\mathrm{CSZ}$ and led to the formation of oxygen vacancies. This oxygen vacancies provide ion transfer and cause the electrical conductivity. Song et al. reported that $\mathrm{NiO}$ could be dissolved up to $0.5 \mathrm{~mol} \%$ in the 8Y-CSZ [16].

The grain interior and grain boundary activation energies for undoped and $1 \mathrm{wt} \% \mathrm{NiO}$ doped $8 \mathrm{Y}-\mathrm{CSZ}$ specimens were calculated using the following Arrhenius equation. The grain interior and grain boundary data were plotted as conductivity as shown in Figs. 6 and 7, by analyzing the temperature $(T)$ dependence of the ionic conductivity $(\sigma)$ and the activation energies for the grain interior and the grain boundary were calculated from the slope of the line obtained from the plot of $\ln \sigma-\mathrm{T}$.

$$
\sigma=\sigma_{0} \exp \left(-\mathrm{E}_{\mathrm{a}} / \mathrm{RT}\right)
$$

where, $T$ is absolute temperature, $\sigma_{0}$ is pre-exponential factor and $E_{a}$ and $R$ are activation energy and gas costant, respectively.

The grain interior activation energies for undoped and $\mathrm{NiO}$ doped 8Y-CSZ specimens are shown in Fig. 6. As can seen from this figure, all data coincided on a straight line. The grain interior activation energy $\left(E_{a}\right)$ values of the undoped and $1 \mathrm{wt} \% \mathrm{NiO}$ doped $8 \mathrm{Y}-\mathrm{CSZ}$ 

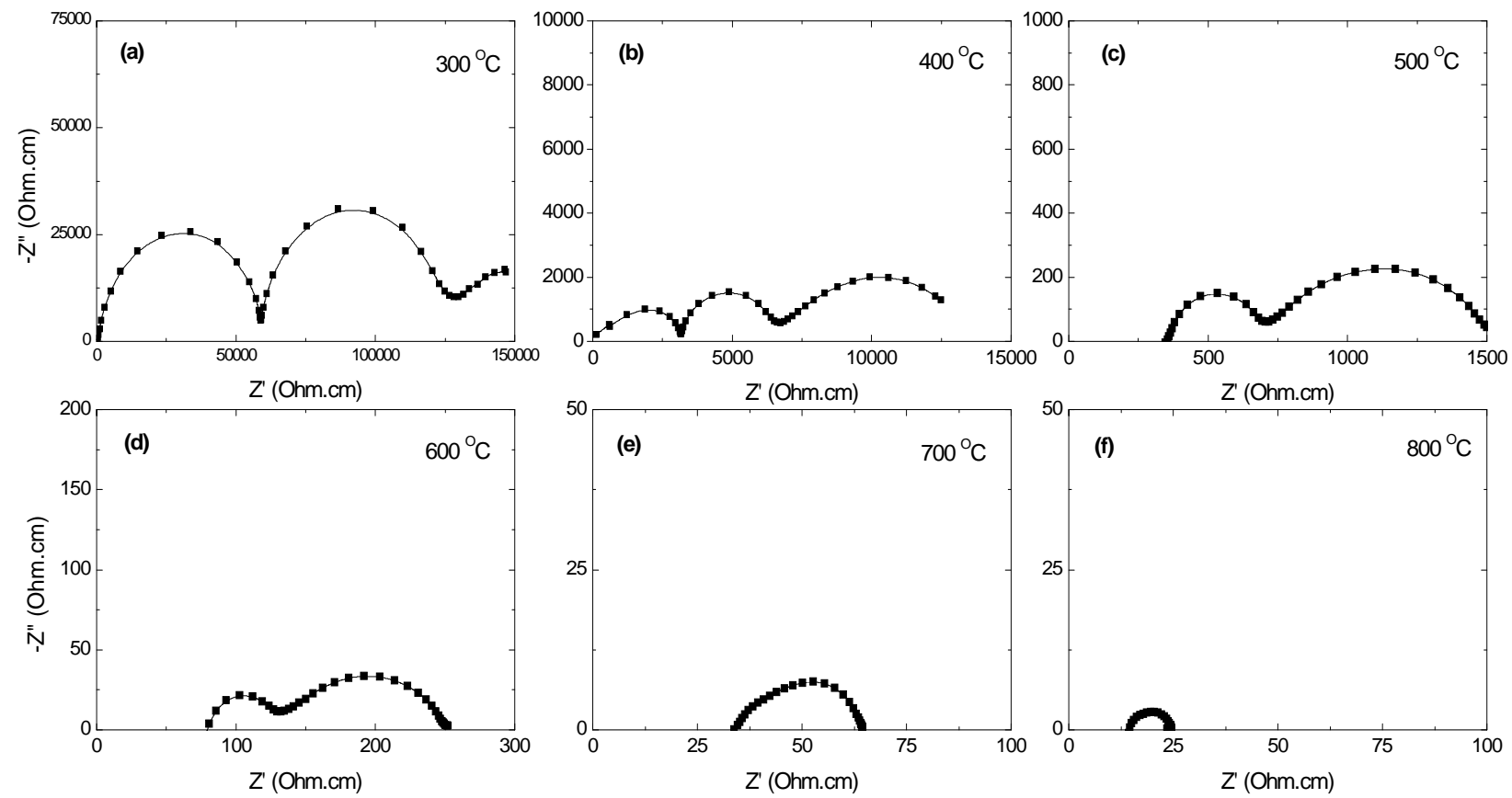

Fig. 4 The ac impedance spectroscopies of $1 \mathrm{wt} \% \mathrm{NiO}$ doped $8 \mathrm{Y}-\mathrm{CSZ}$ at different temperatures.

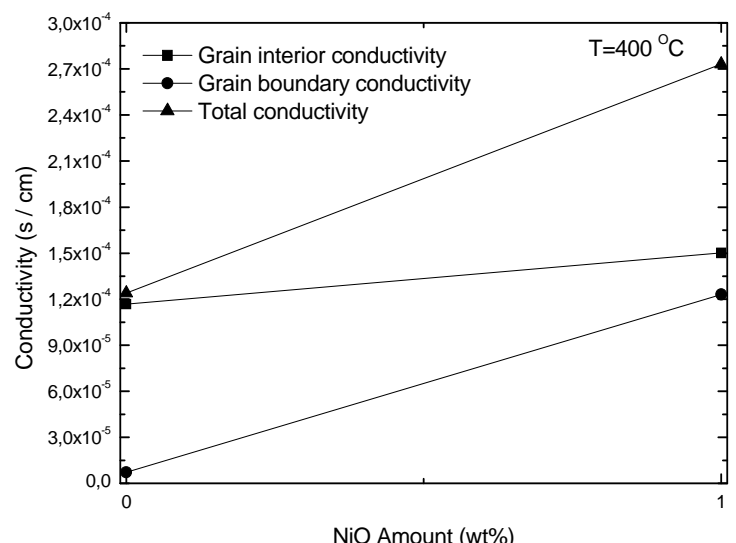

Fig. 5 The change of the electrical conductivities with addition of $\mathrm{NiO}$ at $400{ }^{\circ} \mathrm{C}$ test temperature.

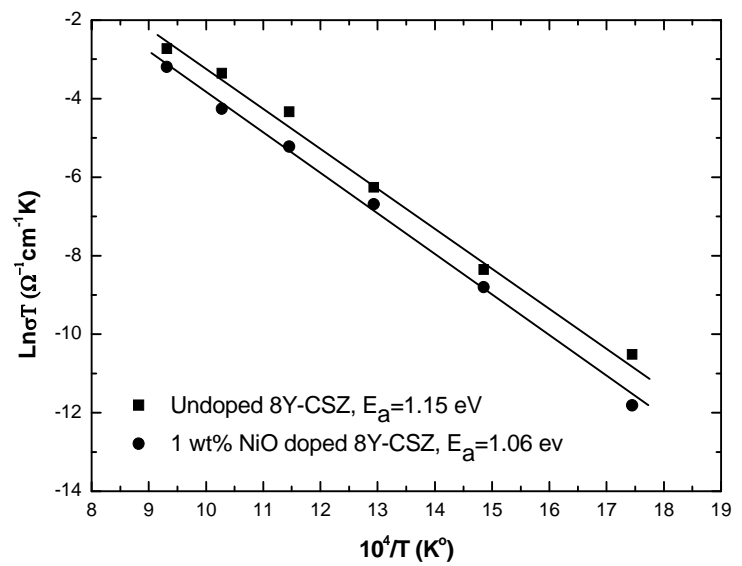

Fig. 6 The grain interior activation energies of the undoped and $1 \mathrm{wt} \% \mathrm{NiO}$ doped $8 \mathrm{Y}-\mathrm{CSZ}$ specimens. specimens were calculated as 1.15 and $1.06 \mathrm{eV}$, respectively. The activation energy results showed that the grain interior ion transport in the $1 \mathrm{wt} \% \mathrm{NiO}$ doped $8 \mathrm{Y}-\mathrm{CSZ}$ would be easier than in undoped $8 \mathrm{Y}-\mathrm{CSZ} .1 \mathrm{wt} \% \mathrm{NiO}$ addition into $8 \mathrm{Y}-\mathrm{CSZ}$ brought about oxygen vacancies in the $8 \mathrm{Y}-\mathrm{CSZ}$ matrix and these oxygen vacancies helped in the ionic transport. Therefore, the grain interior activation energy decreased in the $1 \mathrm{wt} \% \mathrm{NiO}$ doped $8 \mathrm{Y}-\mathrm{CSZ}$.

The grain boundary activation energies $\left(E_{a}\right)$ for undoped and $1 \mathrm{wt} \% \mathrm{NiO}$ doped $8 \mathrm{Y}-\mathrm{CSZ}$ specimens are shown in Fig. 7. The grain boundary activation energy $\left(E_{a}\right)$ values of the undoped and $1 \mathrm{wt} \% \mathrm{NiO}$ doped 8Y-CSZ specimens were calculated as 1.50 and $1.06 \mathrm{eV}$, respectively. Due to $\mathrm{Y}_{2} \mathrm{O}_{3}$ segregation at the grain boundaries in the $8 \mathrm{Y}-\mathrm{CSZ}$, the activation energy value of the undoped $8 \mathrm{Y}-\mathrm{CSZ}$ was higher than $\mathrm{NiO}$ doped 8Y-CSZ.

It is known as the blocking effect of grain boundaries that increased resistance to ion transfer of grain boundaries (according to grain interior resistance). Impurities which existed in the grain boundaries caused blocking of grain boundaries. Specific conductivity of the grain boundary at $8 \mathrm{~mol} \%$ 


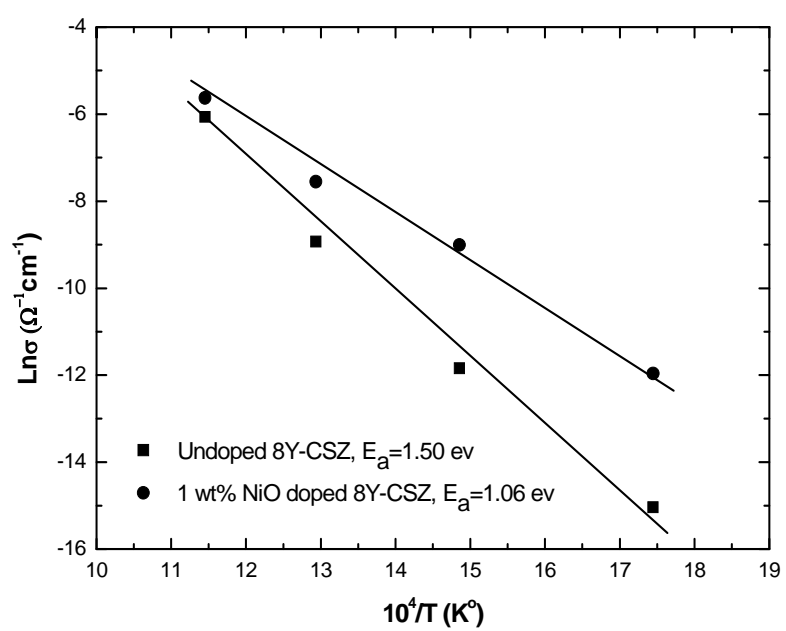

Fig. 7 The grain boundary activation energies of the undoped and $1 \mathrm{wt} \%$ NiO doped 8 Y-CSZ specimens.

yttria-stabilized cubic zirconia (8Y-CSZ) is lower than grain interior $[13,17]$.

If a specimen has more total grain boundary area, it means that this specimen has a lower total conductivity. Guo and Maier pointed out that this internal grain boundary resistance seen in materials at high temperatures might occur as a result of a disappearance of the space charge-oxygen vacancy [13]. As a result of decreased oxygen vacancy in the space charge layer of the grain boundary, a blocking effect of the grain boundary and grain boundary core may occur and can be considered as divided into two space charge layers. Yttria segregation at the grain boundaries of $8 \mathrm{Y}-\mathrm{CSZ}$ are twice as high as at the grain interior. Oxygen vacancy decreases when these defects interact with defects or a mechanism with vanished oxygen vacancy is revealed. $\mathrm{Y}_{2} \mathrm{O}_{3}$ segregation existing at the grain boundaries of 8Y-CSZ brings about a blocking effect of the grain boundary and causes to vanish of oxygen vacancies. Thus, the activation energy of the grain boundary was expected to be higher for the undoped 8Y-CSZ. The addition of a small amount of $\mathrm{NiO}$ into $8 \mathrm{Y}-\mathrm{CSZ}$ reduced the negative effects of $\mathrm{Y}_{2} \mathrm{O}_{3}$ segregation and led to the new transmission paths for ion conduction. Therefore, the grain boundary activation energy of 1 wt $\%$ NiO doped $8 \mathrm{Y}-\mathrm{CSZ}$ is lower than undoped $8 \mathrm{Y}-\mathrm{CSZ}$.

\section{Conclusions}

The addition of $1 \mathrm{wt} \% \mathrm{NiO}$ into $8 \mathrm{Y}-\mathrm{CSZ}$ gave rise to a decrease in the grain size. $\mathrm{NiO}$ could be dissolved in the $8 \mathrm{Y}-\mathrm{CSZ}$ up to $0.5 \mathrm{~mol} \%$. Insoluble $\mathrm{NiO}$ in the $8 \mathrm{Y}-\mathrm{CSZ}$ precipitated at the grain boundaries. The presence of the $\mathrm{NiO}$ precipitation at the grain boundaries of $8 \mathrm{Y}-\mathrm{CSZ}$ restricted the movement of grain boundaries. Therefore, the grain size of $\mathrm{NiO}$ doped 8Y-CSZ was smaller than undoped 8Y-CSZ.

The Ac impedance spectroscopy results showed that the grain interior and grain boundary resistances with addition in a small amount of $\mathrm{NiO}$ decreased increasing temperature. The grain interior resistance of $1 \mathrm{wt} \% \mathrm{NiO}$ doped $8 \mathrm{Y}-\mathrm{CSZ}$ was lower than grain boundary resistance. The grain interior, grain boundary and total conductivities of the $8 \mathrm{Y}-\mathrm{CSZ}$ increased with addition of a small amount of $\mathrm{NiO}$.

\section{References}

[1] E.I. Tiffe, Fuel Cells, Institute of Materials for Electrical and Electronic Engineering, University Karlsruhe, 2003, pp. 44-46.

[2] Introduction to Functional Materials, 2006 http://alpha.qmul.ac.uk/ ugez644/MAT203/fuel_cells.pdf.

[3] Fuel Cells Home Page, 2006, http://yunus.hacettepe.edu.tr/yilser/ yakitpili.htm.

[4] S.C. Singhal, Development of a multilayer anode for solid oxide fuel cells, Solid State Ionics 152-153 (2002) 405-410.

[5] U. Betz, A. Sturm, J.F. Löffler, W. Wagner, A. Wiedenmann, H. Hahn, Microstructural development during final-stage sintering of nanostructured zirconia based ceramics, Materials Science and Engineering A 281 (2000) 68-74.

[6] C.F. Grain, Sintering and heterogeneous catalysis, Materials Science Research, J. Am. Ceram. Soc. 50 (6) (1967) 288.

[7] H.G. Scott, Phase Relationships in the $\mathrm{ZrO}_{2}-\mathrm{Zr}_{3} \mathrm{~N}_{4}$ system, J. Mater. Sci. 10 (9) (1975) 1527.

[8] Z.M. Jarzebski, Oxide Semiconductors, Pergamon Press, New York, 1973, p. 150.

[9] T.E. Mady, J.T. Yates, D.R. Scndstrom, R.J.H. Voo-Rhoeve, Treatise on Solid State Chemistry, (Vol. 6B), Plenum Press, New York, 1976, p. 1.

[10] Y.M. Park, G.M. Choi, Microstructure and electrical properties of YSZ-NiO composites, Solid State Ionics, 120 (1999) 265-274. 
[11] R.M. Batista, E.N.S. Muccillo, Densification and grain growth of 8YSZ containing NiO, Ceram. Int. 37 (2011) 1047-1053.

[12] O.E. Sağlam, An investigation on sinterability and static grain growth behaviour of various amount of $\mathrm{SiO}_{2}$ doped cubic zirconia (8YSCZ), Master Thesis, Ankara, Turkey, 2005.

[13] X. Guo, J. Maier, Grain boundary blocking effect in zirconia: A schottky barrier analysis, Journal of the Electrochemical Society 148 (3) (2001) 121-126.

[14] M. Miyayama, H. Yanagida, A. Asada, Effects of $\mathrm{Al}_{2} \mathrm{O}_{3}$ additions on resistivity and microstructure of yttria-stabilized zirconia, Am. Ceram. Soc. Bull. 64 (4) (1985) 660-664.

[15] J.E. Bauerle, Study of solid electrolyte polarization by a complex admittance method, J. Phys. Chem. Solids 30 (12) (1969) 2657-2670.

[16] X.C. Song, J. Lu, T.S. Zhang, J. Ma, Sintering behavior and mechanisms of NiO-Doped $8 \mathrm{~mol} \%$ yttria stabilized zirconia, Journal of the European Ceramic Society 31 (2011) 2621-2627.

[17] X. Guo, Physical origin of the intrinsic grain-boundary resistivity of stabilized-zirconia: Role of the space-charge layers, Solid State Ionics 81 (3-4) (1995) 235-242. 